\title{
Investigating boredom among EFL teachers
}

\author{
Dino Dumančić \\ University of Zadar, Croatia
}

\begin{abstract}
The aim of this qualitative study was to investigate boredom among Croatian primary and secondary school teachers of English. The data was gathered by means of an open-ended survey that focused on the teachers' experiences with classroom boredom. The findings pointed to different causes of boredom in the Croatian FLT context, such as grammar tasks and uninteresting subject matter. Croatian teachers reported various manifestations of boredom, i.e. cognitive and motivational, as well as diverse emotion regulation strategies employed, such as introducing new content or engaging in physical activity. Majority of the teachers stated that boredom did not affect their instructional quality, however there were those who reported having observed adverse effects in their classrooms.
\end{abstract}

Key words: emotions; L2 teachers; foreign language teaching; teacher boredom; instructional quality.

\section{Introduction}

"Perhaps the world's second worst crime is boredom. The first is being a bore." Jean Baudrillard

Have you even been bored in class? Have you even been a bore in class? These questions may not have been posed that often but that is slowly starting to change. Affective factors have a significant impact on the language learning process (Arnold \& Brown, 1999). How we feel, what we believe, the attitudes we hold will not only have a bearing on how we approach a language but also how we use it and interact with others in class. While numerous studies have addressed motivation in Second Language Acquisition (SLA), for instance Ushioda (2011), Dörnyei (2005, 2009), Tremblay and Gardner (1995), fewer have focused on classroom emotions. Ryan (2007) has confirmed the dominance of motivation research in SLA while indicating a growing interest in emotions with the start of the $21^{\text {st }}$ century. Several au- 
thors, such as Dörneyi and Ushioda (2009), Dewaele (2011), and MacIntyre, MacKinnon and Clément (2009) have underscored the connection between motivation and emotions by stating that emotions act as strong motivators for learners.

As regards classroom emotions, anxiety is among the most researched ones (Dewaele, 2017; Piechurska-Kuciel, 2008; MacIntyre \& Gardner, 1991; Horwitz, Horwitz, \& Cope, 1986), while less research has been conducted on boredom. Boredom is considered one of the prevalent negative emotions in the academic context; moreover, its detrimental effect impacts students' progress. Fisher (1993) described it as an unpleasant, temporary emotion which is accompanied by acute loss of interest and difficulty focusing on a certain classroom activity. Middle-school students, for instance, experience boredom 32\% of the time they spend in class (Larson \& Richards, 1991). There is also evidence that students feel boredom more than they experience anxiety in class (Götz, Frenzel, Pekrun, \& Hall, 2006). Though research on student boredom is increasing in frequency, very little is known about how and when teachers experience boredom in class and how they cope with the emotion. This especially pertains to the context of foreign language teaching which is lacking in research on that topic. It is the hope of this author to remedy that by breaking ground and helping current and future foreign language teachers develop by providing insight into Croatian EFL teachers' experiences with classroom boredom. Specifically, this qualitative study will address the teachers' accounts of boredom with regards to specific classroom activities, reported manifestations of the emotion, the emotion regulation strategies employed, and the effect boredom had on their instructional quality.

\section{Theoretical overview}

\subsection{Academic boredom}

Emotions are viewed as constructs that consist of multiple components, such as affective, physiological, cognitive, expressive, and motivational (Hall \& Götz, 2013). The affective component is at the heart of emotion and one can state that there can be no emotion without the affective experience. Affectively speaking, boredom is considered an unpleasant feeling (Pekrun, 2006). Regarding the physiological component, when a person experiences an emotion, they can observe various bodily processes. For instance, when one feels bored, they will experience low arousal. Furthermore, the cognitive component pertains to the thoughts one starts having as a result of emotional arousal. When a person experiences boredom, their thought processes start reflecting that negative emotional state (e.g. thinking about the slow passage of time). With regards to the expressive component, it covers the visible 
signs, such as facial expressions, body movements or postures that a person experiencing the emotion gives away.

When bored, a person may start yawning or drawing something (Kruk \& Zawodniak, 2018). When it comes to the motivational component, it is important to note that each emotion can instigate certain behavior. It differs from emotion to emotion but in terms of boredom, Pekrun (2006) states that there is a desire to escape the boring situation. Boredom should also be considered from the viewpoint of emotion valence and activation. In other words, boredom is considered a negative emotion (valence), however in terms of activation it is regarded as a deactivating emotion. Physiological deactivation slows the organism down and makes one feel at ease - the extreme case would indicate being close to falling asleep (Pekrun, Muis, Frenzel, \& Götz, 2018).

\subsection{Causes of boredom}

Many researchers have set out to investigate the factors that act as precursors of boredom in the academic context. Many authors (e.g. Robinson, 1975; Miklaus \& Vodanovich, 1993; Titz, 2001) discussed a variety of factors that act as precursors to boredom, while a handful of them reflected on teaching (e.g. Götz, 2004; Stephanou, Gkavras, \& Doulkeridou, 2013) or the EFL context (e.g. Khajavy, Ghonsooly, Hosseini \& Frenzel, 2018). The study carried out by Khajavy et al. (2018) will be discussed in section 2.5. Boredom in the EFL Context.

To start with, Robinson (1975) created a model which delineated situational and personal precursors of boredom at school. The model put forth two types of causes - imminent and distant ones. In the case of imminent causes of boredom, the author listed monotonously instructed classes, absence of goals, perceived pointlessness of the subject, while the distant type of causes is linked to the students' personal life (parents, peers, etc.). Monotony, as mentioned by Robinson (1975), was also reported by Hill and Perkins (1985) as the main antecedent of boredom. The authors believe that boredom might be instigated by the meaningfulness or value of the stimulation.

Several authors discussed situational factors as prominent sources of boredom in the classroom (Fisher, 1993; Miklaus \& Vodanovich, 1993; Titz, 2001; Kanevsky \& Keighley, 2003, Lohrmann, 2008). To illustrate situational factors, the authors mentioned learning material, tasks, level of difficulty, monotony in the classroom among others. An inadequately stimulating setting is what triggers boredom according to Miklaus and Vodanovich (1993). They believe that the teaching/learning material should be adjusted to the students' abilities and achievement. If it is not, boredom will occur. Besides 
monotony, lack of meaning was found to be an even stronger predictor of classroom boredom (Titz, 2001). A similar situation was observed in the case of under/overchallenging students. According to both Titz (2001) and Lohrmann (2008), students that are insufficiently or overly challenged in class will most likely experience boredom.

In addition, various aspects related to instruction have been known to cause boredom as well. Research conducted by Götz (2004) revealed high negative correlations between boredom and clarity of instruction, the structure of the lesson, commitment and the way teachers motivated the students. Though instructional material is one of the instigators of classroom boredom, it is not as prominent as the instructional quality or lack thereof. Lohrmann (2008) attested to this by claiming that students, when asked about the precursors of their boredom in class, primarily focused on the instructional aspect.

More recent research was carried out by Nett, Götz and Daniels (2010), Daschmann, Götz and Stupinsky (2011), Götz and Hall (2014) and Daniels, Tze and Götz (2015) among others. To start with, Daschmann et al. (2011) developed the scale designed to investigate precursors to boredom. The instrument covered eight separate antecedents of boredom: monotony, lack of meaning, opportunity costs, being over-challenged, being underchallenged, lack of involvement, teacher dislike and generalized boredom. Furthermore, research conducted by Götz and Hall (2014) provided results that helped the authors place the antecedents of boredom in three distinct categories: the environment (e.g. monotony), the person (e.g. low control/value), and the environment/person fit (too high/too low difficulty). Students' appraisal of the environment and their personal traits is linked to how they perceive the learning content (e.g. it being above or below their abilities).

Stephanou et al. (2013) stated that teachers can experience a range of unpleasant emotions in the classroom and that they directly affect their work. To illustrate, teachers tend to experience anger, shame, unhappiness, hopelessness, and boredom. When looking into the possible causes, the authors mentioned that these emotions can be instigated by their students' inadequate progress, failed teaching, poor relationship with colleagues or undesirable situations at school.

\subsection{Manifestations of boredom}

Boredom tends to manifest itself in many forms and as such is experienced differently by various individuals. Some notable signs of boredom were reported in a study carried out by Martin, Gaynor and Stew (2006); moreover, the teachers recalled feeling lethargic, stressed, entrapped, lacking ener- 
gy or motivation to do anything. Though they felt the need to change their current state, they were not motivated enough to do anything about it. This finding is in line with Miklaus and Vodanovich (1993) who argued that low/high level of arousal contributed to boredom. When it comes to experiencing boredom in the classroom, students may act like they are pretending to listen to the teacher, or they may simply drift away. Other forms of boredom manifestation among students include talking to others in class, using one's mobile phone, being indifferent, avoiding eye-contact with the teacher and other (Zawodniak \& Kruk, 2018).

\subsection{Coping with boredom}

In order to cope with boredom, one must utilize a range of strategies. Though strategies are used to alleviate the negative effects of boredom, not everyone uses the same ones. One of the goals of research on boredom is to ascertain the most effective strategies that will benefit both the students and teachers in their work. The text below will present several models (e.g. Holahan, Moos \& Schaefer, 1996; Nett, Götz, \& Daniels, 2010) that underscored diverse strategies of coping with boredom, alongside a study carried out by Taxer and Frenzel (2015) which investigated the strategies secondary school teachers used to express positive and negative emotions in school (boredom being one of them). The study also showed intriguing relations between the emotions and other teacher-related constructs, such as self-efficacy.

A notable model focusing on boredom coping mechanisms was proposed by Holahan, Moos, and Schaefer (1996). It encompassed a two-pronged concept: approach/avoidance and cognitive/behavioral coping strategies. The approach strategies indicated facing and attempting to solve the problem, while the avoidance strategies implied avoiding and fleeing from it. The second dimension is related to cognitive/behavioral strategies; moreover, cognitive strategies are used to alter the person's perception of a given situation, while behavioral strategies indicate a person doing something to change it. Gross's (1998; 2015) process model continues in a similar vein by proposing the following processes of emotion regulation: situation selection (approaching or avoiding situations), situation modification (behavioral strategies), attentional deployment (cognitive change - distraction), and response modulation (regulating emotion-expressive behavior).

The following model is a recent one and it was proposed by Nett, Götz, and Daniels (2010). It was based on the previously mentioned concept put forth by Holahan et al. (1996), however it was modified for the individuals who experience boredom. The authors created a questionnaire that addressed these dimensions: approach vs. avoidance and cognitive vs. behavioral. Based on how their respondents used strategies to overcome boredom, 
the authors proposed three distinct groups: Reappraisers, Criticizers, and Evaders. To explain, the Reappraisers used the cognitive approach (e.g. reappraisal) the most and were considered the most adaptable group. The Criticizers earned their name after being vocal about their dissatisfaction and expressing their desire to change the situation. They employed behavioral approach strategies. Lastly, the Evaders opted for the evasion strategies, which meant engaging in self-distraction rather than taking action in attempt to change the given situation.

The research conducted by Taxer and Frenzel (2015) was aimed at exploring which emotions 266 secondary school teachers expressed genuinely, which of them they chose to hide or fake. In addition, the authors focused on the strategies they used and the correlations between their emotions and constructs such as self-efficacy, teacher well-being, and teacher-student relatedness. Given the nature of this paper, the findings presented will be limited to those pertaining to boredom among the teachers. According to the results, boredom was negatively associated with teaching self-efficacy beliefs, as well as teacher-student relatedness. Furthermore, the strongest negative relationship was noted between boredom and teachers' job satisfaction. When it comes to hiding emotions, the strongest positive relationship was observed between hidden boredom and emotional exhaustion.

\subsection{Boredom in the EFL context}

There is a scarcity of research on boredom in the foreign language learning and teaching context. A handful of papers that have focused on experiences students and teachers had with boredom in the foreign language teaching setting exist till this day. Authors such as Kruk (2016), Zawodniak, Kruk, and Chumas (2017), and Kruk and Zawodniak (2018) reported on different aspects of boredom among the students in the foreign language classroom. Other studies, such as the one carried out by Jean and Simard (2011) did not set out to investigate boredom but made a reference to it in the process. The respondents in their study gauged the relevance of different aspects of teaching grammar, such as grammar instruction methods, accuracy, and corrective feedback. Negative appraisals of grammar instruction were observed among a third of the respondents and among the words useless or difficult was the word boring. As regards the teacher boredom, the study carried out by Khajavy, Ghonsooly, Hosseini and Frenzel (2018) made a reference to it alongside other emotions and indicated a dominant cause of boredom.

The fluctuating nature of classroom boredom among high-school students was reported by Kruk (2016). By focusing on students' proneness to boredom and the varying intensity of boredom in different parts of the Eng- 
lish classes, the author found boredom to be in a state of flux; moreover, the level of boredom depended on different elements, such as topics, tasks, activities, and other. According to the results of the study, the students found grammar-related tasks to induce boredom the most, as opposed to tasks that include working on a dialogue or using the Internet to find new information. The study carried out by Zawodniak, Kruk and Chumas (2017) investigated the causes and the main factors that evoke boredom among English philology students during content subjects and language classes. The participants were asked to keep a diary which they used to document their positive and negative experiences, i.e. reasons for interest and engagement vs disappointment and distraction during their classes. The findings obtained pointed to the four key clusters that were related to the students' expectations and disappointments: (1) language activities, (2) content subjects and language classes, (3) teacher behavior, and (4) class preparation and management.

Research conducted by Kruk and Zawodniak (2018) among Polish English Philology students investigated the participants' boredom experiences, changes in its intensity, observed signs of the emotion, as well as the coping strategies they used. The results revealed a varying intensity in boredom among the students throughout the lessons (beginning vs. end of the class), different aspects of the students' boredom (in-class vs. out-class boredom), notable forms of behavior, such as daydreaming or zoning out, and other.

Khajavy et al. (2018) explored the antecedents of pleasant and unpleasant emotions among 11 Iranian EFL teachers. The results indicated a single cause that instigated boredom among the teachers - demotivated or uncollaborative students. This was reported by three out of eleven teachers in the study and it points to the teachers' assessment of failure to reach the engagement goal.

\subsection{Instructional quality}

To facilitate efficacious learning and teaching, there needs to be an environment conducive to those processes. Boredom, as a negative emotion, has a hindering effect on both the learners and teachers. If the teacher is to provide quality instruction, they need to be aware of and be able to cope with the emotion. To illustrate the diverse nature of instructional quality, the author will present Klieme, Pauli and Reusser's (2009) model. The authors presented this comprehensive model by drawing from the previous research paradigms, such as process-product (e.g. Seidel \& Shavelson, 2007) and constructivist (e.g. Pauli \& Reusser, 2006). It considered the following deep structure dimensions of quality of instruction: 1) cognitive activation and deep content; 2) classroom management, clarity and structure; and 3) supportive climate. To illustrate, cognitive activation implies the use of various methods 
of instruction and activities to engage the students cognitively. The aim is to engage the students in problem-solving activities that would require them to integrate the existing knowledge, analyze or evaluate the content. Next, classroom management denotes a clearly structured class where the students are familiar with the rules and know what to expect.

This dimension aims to foster the motivation and engagement in the classroom. Lastly, supportive climate encompasses the emotions and the motivation of the learners. This dimension also refers to teachers who have a good rapport with their students. Such teachers listen to their students, help them, encourage them, validate their ideas and thoughts.

\section{Aim and method}

\subsection{Aim}

The aim of this study was to investigate boredom among Croatian primary and secondary school teachers of English. The focus was on causes of boredom, manifestations of the emotion, emotion regulation strategies, and the effect boredom has on the teachers' instructional quality.

Research questions:

1) What causes boredom among Croatian English teachers during their English classes?

2) How does boredom manifest itself in the teachers?

3) How do the teachers regulate this emotion?

4) How does boredom affect their instructional quality?

\subsection{Method}

\subsubsection{Sample}

The sample consisted of 38 Croatian teachers of English. The teachers were employed in primary and/or secondary schools. The initial number was 39, however upon closer inspection it was uncovered that one teacher submitted a blank survey. That action made it null and void.

\subsubsection{Instrument}

An open-ended survey consisting of five items was used in this study. The first section presented general information required to get a basic understanding of the study: aims, nature of study, its components, and ethics statement informing the participants of the voluntary nature of this study and ensuring their anonymity. The second section presented five open- 
ended items that were designed to examine the previously mentioned aspects related to teacher boredom. The frameworks proposed by Chahkandi, Rasekh, and Tavakoli (2016) and Kruk and Zawodniak's (2018) served as guidelines in the creation of this instrument.

\subsubsection{Procedures}

The instrument was created and administered via Google Forms - a survey administration application. Hoping to reach as many teachers as possible, the author used various channels, such as Senior Advisors with the Education and Teacher Training Agency, county coordinators of teacher training, members of the Croatian Association of Teachers of English (CATE), colleagues, and others. Teachers willing to aid in the process of dissemination proceeded by sharing the link of the survey among their colleagues.

\subsubsection{Analysis}

Once the author obtained the data, the following step included printing it and subjecting it to directed content analysis (Hsieh \& Shannon, 2005). Given the qualitative character of the study, this type of analysis involves reading the content, highlighting relevant passages, coding them, and clustering them into categories. It is worth mentioning that categories in this study had already been pre-determined by the items; furthermore, the categories were as follows: cause(s) of boredom, signs of boredom among the teachers, emotion regulation strategies used by the teachers, and the effect boredom has on quality of teaching.

\section{Results}

This section will present the results according to the order of said categories in this study. Also, the findings will be discussed in order of their frequency. This means that the most prominent examples of each sub-section will be portrayed first, only to be followed by less frequent ones.

Causes of Boredom. The qualitative analysis yielded different causes of boredom which were organized in six distinct groups: subject matter, students, tasks and activities, student assessment, teaching aids and materials, and teaching methods. Starting with the teaching content, it was the most prominent category and it depicted content that evoked boredom the most in the teachers, for instance grammar-related content. The teachers agreed that grammatical tasks caused boredom the most. One teacher reported that when "we (as a class) focus on grammar parts, if they (students) find it chal- 
lenging, their minds tend to wander." Another teacher explained that they get bored when they deal with "Grammar tasks, drilling, correction of the same grammar mistakes, e.g. Simple Present -es in the $3^{\text {rd }}$ person singular."

The second element that caused boredom was named subject matter and it incorporated uninteresting lessons and topics. The teachers clarified that certain lessons/topics presented in textbooks were repetitive, unimaginative, and outdated. According to one teacher, "it is sometimes tedious to teach the same content over and over again..." Another teacher explained that topics, such as "ecology", do not pique students' interest at the present time. In their words, "It is mostly subject matter like ecology because students are not interested, do not want to discuss it (they have nothing to say)..." The following example is quite unexpected as one teacher stated that "the subject matter of films and music evoked boredom in me and my students who are not interested in these topics whatsoever."

The following category, labeled students, pertains to students' behavior, motivation, and knowledge. With regards to students' behavior, several teachers claimed to have been bored by unresponsive students in the classroom. Boredom, as stated by one teacher, "is caused by non-motivated students whose inactivity can be rather overwhelming." Students' lack of knowledge was another interesting factor. Having to go over the same content several times owing to students' lack of focus or knowledge proved difficult and boring for some of the teachers. One of them replied that "low level of knowledge of some students, when they don't understand topics or grammar can cause boredom." The last component related to students was named lack of motivation. This would indicate that the teachers experienced boredom when they observed their students' absent-mindedness or lack of motivation. Some teachers even highlighted constant repetition as an example, claiming that "most of the time, it (boredom) is caused by lack of motivation among some students, repeating always the same language corpus ..." Similarly, another teacher revealed that "boredom is caused by constant repeating of same things to the same students knowing they are not listening."

The upcoming category was called tasks and activities. It addressed repetitive tasks, undemanding tasks, and other types of activities, such as reading exercises, translating sentences or workbook exercises that students do on their own. The first two will be discussed as they are the most notable examples, however the remaining ones will not due to scarcity of information provided. In terms of repetitive tasks, several teachers stated that certain tasks tend to emerge often in the process of foreign language teaching, and they can be instigators of boredom. According to one of the teachers, boredom comes as a "natural reaction...quite often the result of long, repetitive reinforcement and drilling exercises..." The repetitive nature of such tasks 
was also mentioned by another teacher who said they felt bored of "repeating the same things over and over again". Simple or undemanding tasks can also evoke boredom, not only among teachers but also among students. According to some teachers, these tasks may require students to supply a single word, finish the sentence, and so forth. One teacher called them "noncreative tasks" and provided "copy the sentences" as an example. Another teacher voiced a similar opinion by claiming that tasks, such as "copying new words from the board", induced boredom.

The following cause that precipitated boredom among the teachers was student assessment. Two concrete examples were offered: taking tests and grading students. Firstly, several teachers agreed that the process of testing or taking tests made them experience boredom as there was little for them to do but stand around and wait. The words of one teacher confirm this "There is only one thing that causes boredom in my class - when my students write tests." Another teacher confirmed it by stating that "I don't like tests and monitoring students so they wouldn't copy." Besides testing, grading students also caused boredom among the teachers. With regards to grading, the teachers implied different things, such as grading homework, papers, essays or even exams. In the words of one teacher, "boredom is sometimes caused by activities that last long, like correcting homework and essays." Alongside exams, which cause boredom, another teacher responded that they felt bored "while the students are writing essays". One interesting example involved the evaluation of students' oral proficiency. In the words of one teacher, "The worst part of my teaching is definitely evaluation (oral exam)."

Next, teaching aids and materials proved to be the cause of boredom among the teachers as well. They mainly focused on textbooks as the predominant cause of the emotion, followed by a lack of multimedia in the classroom. Starting with textbooks, many teachers agreed that "boring (outdated) material", "bad textbooks" or simply "the same textbook" made them feel less interested in the class. This, undoubtedly, reflected negatively on the students. According to them, such books were quite likely to evoke boredom in those who use them. This is supported by the words of one teacher who stated that "boredom is caused by boring books chosen several years ago..." With regards to the latter cause that involves multimedia, one teacher simply responded that, alongside lack of motivation among the students, "lack of multimedia in the classroom" was what attributed to their boredom.

The final category pertained to teaching methods. More accurately, the teachers addressed teaching methods that students do not like and using the same methods frequently. The first cause was a dominant one and it revolved around frontal teaching as a proven but less modern method that has been used for a long time. One teacher, for instance, stated that students do 
not like methods "such as frontal teaching or doing exercises from the workbook". Another teacher addressed the lack of inspiration and time among the teachers which results in outdated methods. They said that "children are not always inspired to do group work." On the other hand, using the same methods can also be a detrimental move. In such cases both the teachers and students get used to the same 'flow' of teaching and do not feel motivated to participate. According to one teacher, "boredom is caused by the expected methods. If you do not change things and bring novelties into the classroom." Similarly, another teacher said that boredom arises if "the teacher is not capable of presenting it (content) in an amusing way."

Manifestations of Boredom. Teachers in this study provided numerous examples of how boredom usually manifests in them while teaching. These forms of manifestations were organized around five groups: cognitive, expressive, motivational, no visible signs, and no boredom experienced. The first component to be discussed is the cognitive type. The results uncovered diverse examples, such as lack of creativity/imagination, hoping the class to be over, drifting away, and loss of concentration. Firstly, lack of creativity/imagination was attributed to the cognitive state in which the teacher found it difficult to provide an explanation to the students. While one teacher revealed they were "giving random answers", the other elaborated that "my boredom is usually associated with the impossibility of being creative when I have to keep on giving continuous explanations to uninterested students."

In terms of hoping the class to be over, a couple of teachers connected boredom with the slow passage of time or the desire to expedite things and finish the class. According to one teacher's experience, "I can sense that I am doing some activity just to get it over with." The same can also be gathered from the words of another teacher who said they "look at my watch constantly, it seems as though time passes slowly..." Boredom can make some teachers drift away at work. This would indicate the absent-mindedness which is closely connected to a loss of concentration. One teacher explained that boredom usually manifests itself in them in the form of "looking out the window, especially when students do their tests." Another curious example of drifting away includes a teacher noticing "specific details around the classroom that I have not noticed before."

The second most frequent is the expressive type. It entailed visible facial expressions, postures or any kind of body movement. The most notable example included yawning which occurred in different situations. For instance, one teacher explained that "I become less active (sluggish), there is a drop in communication, I start yawning and just let them complete the tasks in the book" when they experience boredom. Another example included a teacher telling students how they feel. This action demonstrates how a 
teacher aims to overcome boredom by being frank with the students. Though this may be regarded as a type of expression, it may also be considered a form of emotion regulation. One teacher explained how "I tend to tell my class how I feel and ask them if they would rather do something else instead." In a similar vein, another teacher claimed to "tell my students: this is boring, but we can do it." Another example related to this section involved teacher slowing/sitting down. The example is self-evident as both the students and teachers can gain a plethora of information by observing paralinguistic cues. In this case, the teachers reported slowing or sitting down as a result of boredom. According to one teacher, boredom is reflected in their "non-energetic body talk". Another example was already stated earlier in this section when one of the teachers reported getting "less active" or "sluggish".

Motivational is the upcoming type of manifestation of boredom. The results showed two different forms of it: loss of enthusiasm/interest and desire to change activity. When it comes to the loss of enthusiasm or interest, several teachers confirmed it with regards to experiencing boredom. When asked how boredom manifests itself in them in the classroom, they responded "I teach but I am not motivated. I do not enjoy in the teaching process..." or "I also get bored and lose enthusiasm". The following example, called desire to change activity, goes in line with the accounts provided in the previous section where two teachers openly admitted feeling bored and wanting to change the activity. The same desire was observed in another teacher who explained that boredom makes them want to "...change the activity (I get a little bit annoyed) which I almost always do. Because I don't want pupils to see that I am bored."

This section presents a somewhat different type of boredom manifestation; likewise, it points to a complete absence of visible signs of the emotion. This is not to say that the teachers in question did not experience boredom, rather that they chose not to express it in front of their students. Several teachers in this study confirmed this in their accounts. For instance, one teacher explained there were "...no physical signs, I just cannot wait for a class to be over." Another teacher stated that "I am bored, but I still smile and explain everything as it is for the first time. I think there are no observable signs of my boredom." Finally, one teacher simply said they did not show any signs of boredom because "it's not professional."

Lastly, when inquired about possible manifestations of boredom, five teachers admitted showing no signs of boredom because they did not experience the emotion at all. Some of them provided explanations as to why that is, for example "I am never bored when I teach. I'm bored when I have to take part in certain courses I don't find interesting..." or "I am sometimes impatient, but never bored." Another teacher attested to their lack of bore- 
dom by stating "This question suggests that I am bored with activities I prepared for my class. If I as a teacher were bored, how would that affect my students?"

Emotion Regulation. This section is devoted to emotion regulation strategies reported by the teachers in this study. The goal was to get insight into their process of overcoming boredom in the classroom, namely their use of coping mechanisms. The results revealed seven types of emotion regulation strategies: introducing different activities/tasks, physical activity, engaging students, suppression, cognitive change and attention deployment, playing music, and no desire to regulate.

Starting with the largest category, many teachers admitted introducing different tasks/activities to lessen the feeling of boredom. Similar cases were presented earlier in this paper where it was noted that certain actions (e.g. expressing boredom and wanting to move to other tasks) may be considered emotion regulation strategies. The teachers in this study offered several reasons for their actions. One explained they "...ignore textbooks and include some original activities." Another teacher said they "...search for different types of tasks, using new applications, video materials, etc."

Using physical activity was another example of overcoming boredom. Some teachers admitted resorting to it in hopes of changing the classroom dynamic. Physical activity subsumes examples such as stretching, walking, engaging in music-led movement, and others. In the words of one teacher, they "stand up if I'm sitting or start walking to engage myself in physical activity and get to the feeling that something is happening..." Another teacher confirmed this by saying they "...walk it off or start talking to students..." One of the interesting examples includes "introducing some short activities, especially TPR activities" hoping to energize themselves and the students.

When it comes to engaging the students, some teachers reported moving beyond using physical activities and attempting to make the class (or certain activities) conversational, as well as using those forms of teaching that would facilitate students' oral production. To illustrate the first form, one teacher responded that they "reduce the emotion by talking more with students and sometimes positively reacting to their comments and jokes." Another example depicted a teacher who would "try to make students get more involved into an open discussion..." In case of the second form, one teacher said they "change the task and introduce some joke or pair work, group work on the topic."

The remaining categories were equal in their frequency. Starting with suppression, two teachers admitted resorting to this strategy. They did not show their emotions to the students as they felt them, rather they chose to mask or fake them. When asked how they regulated boredom, they re- 
sponded with "I bear with it" or "I don't show it in front of the class. I try to find something that I'm interested in." Next, some teachers revealed they engaged in cognitive change and attentional deployment. Cognitive change is defined as changing the way a teacher views the situation so they could alter its emotional significance. One teacher reported they "try to imagine that I am a student and that I have to attend my lessons. Then I know if something is boring or not." Attentional deployment, on the other hand, is another strategy that teachers use to direct their attention in the classroom so they could influence how they are feeling. In other words, they are distracting themselves from being bored. One teacher revealed that they "usually look for optimistic and happy faces in the class" to cope with boredom.

Another form of dealing with boredom is playing music. One teacher claimed that playing music in the classroom, along with other activities, such as getting students "more involved into an open discussion" seem to help me and my students. Though music was indirectly associated with the previously mentioned TPR example, another teacher explained they "try to switch to some other activity or I put some music in the background." Finally, it should be noted that some teachers did not want to regulate their boredom. That form was simply called no desire to regulate. According to these teachers, emotions should be accepted as they are and not modified in any way. In the words of one teacher, it is obvious that they "don't regulate it at all." They further elaborated by stating that "I am aware of the emotion and know why it's there, so I don't fuss about it. I think it's a very normal response in that specific situation."

The Effect of Boredom on Instructional Quality. The final section of the survey focused on the teachers' experiences with boredom and the effect it had on their instructional quality. Three categories emerged from the qualitative analysis: no effect, negative influence, and attempts at boredom prevention. The largest number of participants belongs to the No effect group; moreover, these teachers admitted experiencing boredom on occasion but strongly attesting it had never affected their quality of teaching. One teacher supported this by stating that "Having to cope with boredom can be a real stumbling block...but a warm rapport and positive approach towards my students proved to be efficient strategies to fight my feelings of boredom." Another teacher replied that they "...rarely feel bored because I love my job and I try to make it interesting, so I don't allow boredom to affect the quality of my teaching."

A somewhat smaller group of teachers considered boredom as detrimental to their quality of teaching. They considered its negative influence by elaborating that boredom can affect not only them, but also their students, their teaching efficacy, teaching outcomes, and so on. One teacher revealed that when they feel bored, they tend to "just go through the activities quick- 
ly." With regards to students, one teacher said that "I become boring to my students, I guess." Regarding teaching efficacy (or one aspect of it), another teacher claimed that boredom "affects my choice of activities the most. I implement various competitive games, short engaging activities, add some new activities to avoid being bored..." Finally, one of the teachers touched upon fatigue in connection to boredom by admitting that "boredom makes me tired."

Lastly, several teachers in this study reported making attempts to prevent boredom so it would not affect their quality of teaching. According to one teacher, "I try to prevent it (boredom) altogether. If I find a topic or subject boring while I'm preparing for the lesson, I try to present it in some way that is interesting and engaging for me, so it would be as fun for the students." Another answer showing similar attempts came from a teacher who explained that they "do everything in my power for it (boredom) not to surface too much." The results also presented a teacher's response that was somewhat contradictory in nature. While signifying the absence of influence boredom has on teaching quality, it also pointed to a form of regulation; however, the teacher claimed that boredom "doesn' $t$ " affect their quality of teaching. "I don't show it. I act like I enjoy it."

\section{Discussion}

The aim of this study was to investigate boredom among Croatian primary and secondary school teachers of English. More specifically, the goal was to examine the causes of boredom, various forms of manifestation, the emotion regulation strategies used, and the effect boredom had on their quality of teaching. This section will discuss some limiting conditions of the study and then review the findings according to the previously presented research questions.

Limiting Conditions. One of the limiting conditions was the sample size. Though it was adequately large for a qualitative study of this design, the results obtained cannot be generalized. Another limiting condition was the instrument used; moreover, it utilized open-ended items which allowed the teachers freedom to express themselves, however it was limited as it did not allow for further (spontaneous) questions. Using an interview in the future might elucidate this phenomenon by investigating other aspects, such as parts of class during which boredom is experienced, class preparation/lesson planning process, teacher development and so forth. Providing socially desirable responses should also be addressed as the teachers tend to describe things according to how they believe they should be, rather than how they truly are. Also, the duration of the study might be considered a limiting condition. The current study is cross-sectional in nature and as such 
prevents the author from making conclusions related to causal connections. Conducting a longitudinal study might provide a better insight into the relations between boredom, its causes and end-results.

Discussion of Findings. The findings will be discussed according to the research questions posed in this study and connected to prior research conducted on the topic. It should be noted that not every finding could be tied to prior research on teacher boredom due to its scarcity. In cases where the author was unable to relate the findings to studies on teacher boredom, research on students was used instead.

1) What causes boredom among Croatian English teachers during their English classes?

The results of the qualitative analysis showed the teaching content to be a major instigator of boredom. More precisely, grammar-related content caused boredom the most among the teachers and their students. This finding goes in line with the findings reported by Jean and Simard (2011), Kruh and Zawodniak (2018), and Kruk (2016). Jean and Simard's results showed grammatical tasks to be mechanical and not very interesting to the learners. Kruk and Zawodniak's, as well as Kruk's, studies confirmed this by stating that both high school and university students experienced boredom most when dealing with grammatical tasks and that they regarded these types of tasks as similar and repetitive. It can be assumed that the students' lack of interest in grammar-related content reflected on the teachers' motivation to teach it. When students show interest and high motivation in the classroom, it promotes teachers' positive emotions such as enjoyment for teaching and satisfaction (Frenzel, Becker-Kurz, Pekrun, Götz, \& Lüdtke, 2018).

The second emerging cause of boredom was the subject matter, or the lessons and topics covered in the foreign language classroom. According to the results of the study, the lessons and topics were described as unimaginative, repetitive, and outdated. As such, they did not motivate or inspire the students or the teachers to invest additional effort into their work. This can be connected to another source of boredom - tasks and activities. The teachers in the study recalled undemanding tasks to be detrimental to their instruction and creativity. Inadequate activities or tasks that did not meet the students' needs and that evoked boredom were also reported by students in the study conducted by Kruk and Zawodniak (2018). This also goes in line with the results reported by Zawodniak, Kruk and Chumas (2017) which showed that one of the antecedents of boredom among the students is content subjects and language classes. Whether it be the content or the tasks, insufficient difficulty can negatively reflect on both the students and teachers. This was corroborated by Götz and Hall (2014) who explained that a student appraises the environment and personal characteristics in relation to learning content. Boredom will occur if the tasks are deemed easy or not 
difficult enough (Lohrman, 2008).

Students were another prominent cause of teacher boredom in this study. To be more exact, their behavior (e.g. unresponsiveness), low motivation or lacking knowledge acted as precursors of boredom among the Croatian EFL teachers. This finding partly corresponds to Stephanou and colleagues' (2013) assertions that teachers tend to experience negative emotions, among which is boredom, when they observe low level of progress among their students. In addition, Khajavy and colleagues' (2018) study on boredom among Iranian EFL teachers specifically pointed to a predominant cause of teacher boredom - students' demotivation and unwillingness to collaborate. This seems to be a pervasive factor in both the Iranian and Croatian education context as students' lack of participation directly and negatively impacts the teachers' motivation and self-efficacy beliefs.

The following cause of boredom was student assessment. In other words, taking tests and grading students. Taking tests or testing was dominant and it was described as a situation in which the students were busy tending to their tests and the teachers had little or nothing to do. This, in turn, evoked boredom in them. In the absence of pertinent research that could back this finding, the author will attempt to make a connection to a concept that might be of similar nature instead. Though not exclusively teacher related, Daschmann (2013, p. 57) proposed a scale of precursors to boredom which incorporated lack of involvement as one of the items. She described it as "the extent to which students feel bored when their teacher does not integrate them in class interaction." Bearing this in mind and viewing it through the prism of teaching, this might help explain why Croatian EFL teachers experienced boredom while monitoring their students. Lack of involvement translated as being unable to participate and engage with students in class; moreover, such a state was undoubtedly unnatural to the teachers as they were the ones motivating their students and providing them with opportunities for learning.

As regards teaching aids and materials, the teachers in this study underscored a single prevailing cause of their boredom - the textbook. According to their reports, the textbooks they used were characterized as bad, outdated and boring. In addition, they not only evoked boredom in themselves but also their students. This finding corresponds to Miklaus and Vodanovich's (1993) statement that teaching/learning materials need to cater to the students' proficiency and achievement. If that criterion is not met, boredom will appear. Götz (2004) reached a similar conclusion when the results of his research pointed to a positive correlation between instructional materials and boredom. Failure to stimulate the students through the teaching materials and the students' inability to establish meaning in what they are doing will most certainly lead to monotony and boredom (Titz, 2001). 


\section{2) How does boredom manifest itself in the teachers?}

The results showed that the teachers in this study reacted differently to boredom in class. First, teachers recalled boredom interfering with their cognitive processes, for instance they had trouble remembering what they wanted to say or explaining something to students. They also drifted away, kept looking at their watch, out the window, and so on. University students of English philology also remembered looking at their watch, yawning, thinking of something else while attending classes they found less interesting (Kruk \& Zawodniak, 2018).

Moreover, the teachers reported visible manifestations, such as yawning, sitting/slowing down or telling students that something is boring (e.g. a certain topic). The final example of verbalizing one's feelings in attempt to overcome them was also reported by Nett, Götz, and Daniels (2010). According to the authors, people who engage in such strategies are called criticizers because they believe a situation can be modified if they protest.

Finally, teachers recalled boredom affecting their motivation. They showed it by being less interested in the activity they were engaged in or the class in general (e.g. the feeling of slow passage of time and them wanting it to be over soon). In addition, boredom made some of them want to change the activity; however, this goes in line with the earlier mentioned verbalization of boredom in front of students and expressing desire to change it. This will be discussed further in the upcoming section. This finding, alongside the one above, coincides with the results of the study conducted by Martin, Gaynor and Stew (2006). The authors clearly stated that teachers experiencing boredom lack the motivation to do anything and they become lethargic in class (which is quite visible to their students).

3) How do the teachers regulate this emotion?

When asked about their coping with boredom in the classroom, the dominant theme was related to introducing different tasks or activities. Teachers admitted opting for something more interesting/original as a means of overcoming boredom. This proactive type of behavior is in line with the behavior approach delineated by Nett et al. (2010) and Holahan et al. (1996). To illustrate, students who are bored may utilize a behavioral approach strategy in the hopes of initiating change that would reduce the effects of boredom. In addition, this finding may also be tied to Zawodniak and coleagues' study in which Polish university students voiced their concerns related to lack of variety of tasks, among other things. The students in question were loath to do a certain type of tasks which caused boredom (Zawodniak, Kruk, \& Chumas, 2017).

Next, physical activity was another major coping strategy reported by the teachers. This would indicate that the teachers felt the need to move around 
or involve students in physical activity to down-regulate the unpleasant emotion. Using physical activity, among other things, as a way of reducing boredom is in line with response modulation of Gross's (2015) process model of emotion regulation. The author states that engaging in physical exercise may help alleviate the effects of negative emotions.

When it comes to student engagement, the teachers revealed initiating interaction with their students to regulate their boredom. This type of behavior can be observed in both teachers and language students. While teachers make jokes or engage students in casual talk when feeling bored, students use their phones or talk to their colleagues during class (Kruk \& Zawodniak, 2018). This finding is also consistent with Gross's (2015) response modulation strategy as it refers to a person's direct attempt to influence the experiential and behavioral aspects of the emotional response. In other words, the teachers in this study modified their behavior in order to positively affect their teaching and their students' learning experience.

4) How does boredom affect their quality of teaching?

When it comes to the effect boredom has on teaching quality, the prevalent finding pointed to a negligible influence or no influence at all. This was confirmed by the majority of the teachers who stated that they experienced it rarely or not at all. The ill-effects of boredom were combatted through positive aspects of their profession, such as good rapport with students, teacher development seminars, and others. This is supported by Klieme et al. (2009) who asserted that ensuring a supportive climate in the classroom promotes the quality of teaching.

The second most frequent theme indicated the negative effects boredom has on teaching quality. This was reported by a smaller group of teachers who correlated their experiences with boredom to their performance, as well as their students' emotional state and performance. The teachers' actions aimed at maintaining the quality of instruction and diminishing the illeffects of boredom involved activating the students by means of various methods and masking how they truly felt. As far as the first example is concerned, it corresponds to Klieme et al.'s (2009) notion of cognitive activation. Such activation assures the quality of learning and teaching by engaging the students with the teaching content. The latter example, however, goes in line with Gross's (2015) expressive suppression which is used to inhibit current emotional behavior. In the case of the teachers in this study it can be assumed that they feared their boredom, if observed, would 'infect' their students. Such an occurrence would most likely detract from the envisioned instructional quality. 


\section{Conclusion}

Boredom in the academic context is considered one of the most prominent emotions experienced by students across all levels. Being a negative and deactivating emotion, it affects one's cognitive and motivational processes and diminishes the quality of work. By focusing on student boredom, the research conducted so far has shown a variety of causes evoking the emotion, established the connection between boredom and different aspects of learning and teaching, as well as discussed strategies used to regulate it. Though research on teacher emotions is on the rise, there is a dearth of studies on teacher boredom. This study attempted to provide insight into that dimension of teacher emotions and relate it to the foreign language teaching context. The results established the presence of boredom among Croatian teachers of English and they uncovered numerous factors that instigate it. This study has important pedagogical implications for both foreign language teaching and teacher education in general. By facilitating further research on the topic, pre and in-service teachers can learn to modify their instructional strategies and materials to counter the ill-effects of boredom. This will, in turn, enhance their teaching resilience and self-efficacy. If teachers are to provide quality instruction, maintain their well-being, have good rapport with their students, and feel self-efficacious, they need to experience positive emotions more and be able to counter the negative ones through the application of a specialized set of skills acquired during teacher education courses. Boredom notwithstanding, being aware of one's emotions and knowing how to regulate them is a prerequisite for ensuring the teachers' self-confidence, autonomy, efficiency, as well as enriching the environment in which they establish relations with their students.

\section{References}

Arnold, Jane, H. Douglas Brown (1999). A map of the terrain. Arnold Jane, ed. Affect in Language Learning. Cambridge: Cambridge University Press, 1-24.

Chahkandi, Fatemeh, Abbas Eslami Rasekh, Mansour Tavakoli (2016). Efficacious EFL Teachers' Goals and Strategies for Emotion Management: The Role of Culture in Focus. Iranian Journal of Applied Linguistics (IJAL) 19.1: 35-72.

Daniels, Lia M., Virginia M.C. Tze, Thomas Götz (2015). Examining boredom: Different causes for different coping profiles. Learning and Individual Differences 37: 255-261.

Daschmann, Elena C., Thomas Götz, Robert H. Stupnisky (2011). Testing the predictors of boredom at school: Development and validation of the precursors to boredom scales. British Journal of Educational Psychology 81: 421-440.

Daschmann, Elena C. (2013). Boredom in School from the Perspectives of Students, Teachers, and Parents. Doctoral Dissertation. Konstanz: Universität Konstanz. 
Dewaele, Jean-Marc (2011). Reflections on the emotional and psychological aspects of foreign language learning and use. Anglistik: International Journal of English Studies 22.1: 23-42.

Dewaele, Jean-Marc (2017). Are perfectionists more anxious foreign language learners and users? Gkonou, Christina, Mark Daubney, Jean Marc Dewaele, eds. New Insights into Language Anxiety: Theory, Research and Educational Implications. Bristol: Multilingual Matters, 70-91.

Dörnyei, Zoltán (2005). The Psychology of the Language Learner: Individual Differences in Second Language Acquisition. Mahwah, New Jersey/London: Lawrence Erlbaum Associates.

Dörnyei, Zoltán (2009). The L2 motivational self system. Dornyei, Zoltán, Ema Ushioda, eds. Motivation, language identity and the L2 self. Bristol: Multilingual Matters, 9-42.

Dörnyei, Zoltán, Ema Ushioda, eds. (2009). Motivation, language identity and the L2 self. Bristol: Multilingual Matters.

Fisher, Cynthia D. (1993). Boredom at work: A neglected concept. Human Relations 46.3: 395-417.

Frenzel, Anne C., Betty Becker-Kurz, Reinhard Pekrun, Thomas Götz, Oliver Lüdtke (2018). Emotion transmission in the classroom revisited: A reciprocal effects model of teacher and student enjoyment. Journal of Educational Psychology 110.5: 628-639.

Götz, Thomas (2004). Emotionales Erleben und elbstreguliertes Lernen bei Schülern im Fach Mathematik [Students' Emotions and Self-regulated Learning in Mathematics]. München: Herbert Utz Verlag.

Götz, Thomas, Nathan C. Hall (2014). Academic boredom. Pekrun, Reinhard, Lisa Linnenbrink-Garcia, eds. International Handbook of Emotions in Education. New York: Routledge, 311-330.

Götz, Thomas, Anne C. Frenzel, Reinhard Pekrun, Nathan C. Hall (2006). The domain specificity of academic emotional experiences. Journal of Experimental Education 75. 1: 5-29.

Gross, James J. (1998). The emerging field of emotion regulation: An integrative review. Review of General Psychology 2.3: 271-299.

Gross, James J., ed. (2015). Handbook of Emotion Regulation (second edition). New York: The Guilford Press.

Hall, Nathan C., Thomas Götz, eds. (2013). Emotion, Motivation, and Self-regulation: A Handbook for Teachers. Bringly, UK: Emerald Group Publishing.

Hill, Austin Bradford, Perkins, R. E. (1985). Towards a model of boredom. British Journal of Psychology 76.2: 235-240.

Holahan, Charles J., Rudolf H. Moos, Jeanne A. Schaefer (1996). Coping, stress resistance, and growth: Conceptualizing adaptive functioning. Zeidner, Moshe, Norman S. Endler, eds. Handbook of coping. Theory, research, applications. New York: John Wiley \& Sons, 24-43.

Horwitz, Elaine Kolker, Michael B. Horwitz, Joann Cope (1986). Foreign language classroom anxiety. The Modern Language Journal 70.2: 125-132.

Jean, Gladys, Daphnée Simard (2011). Grammar teaching and learning in L2: Necessary, but boring? Foreign Language Annals 44.3: 467-494. 
Kanevsky, Lannie, Tacey Keighley (2003). To produce or not to produce? Understanding boredom and the honor in underachievement. Roeper Review 26.1: 20-28.

Klieme, Eckhard, Christine Pauli, Kurt Reusser (2009). The Pythagoras study: Investigating effects of teaching and learning in Swiss and German mathematics classrooms. Janik, Tomas, Tina Seidel, eds. The Power of Video Studies in Investigating Teaching and Learning in the Classroom. New York, NY: Waxmann Publicing Co., 137-160.

Kruk, Mariusz (2016). Investigating the changing nature of boredom in the English language classroom: Results of a study. Dłutek, Anety, Danuty Pietrzak, eds. Nowy wymiar filologii. Płock: Wydawnictwo Naukowe Państwowej Wyższej Szkoły Zawodowej w Płocku, 252-263.

Kruk, Mariusz, Joanna Zawodniak (2018). Boredom in practical English language classes: Insights from interview data. Szymański, Leszek, Joanna Zawodniak, Agnieszka Łobodziec, Marek Smoluk, eds. Interdisciplinary views on the English language, literature and culture. Zielona Góra: Uniwersytet Zielonogórski, 177191.

Larson, Reed W., Maryse H. Richards (1991). Boredom in the middle school years: Blaming schools versus blaming students. American Journal of Education 99.4: 418-443.

Lohrmann, Katrin (2008). Langeweile im Unterricht (Boredom in Class]. Münster: Waxmann.

MacIntyre, Peter D., Robert C. Gardner (1991) Methods and results in the study of anxiety and language learning: A review of the literature. Language learning 41: 85-117.

MacIntyre, Peter D., David P. MacKinnon, Richard Clément (2009). From integrative motivation to possible selves: The baby, the bathwater, and the future of language learning motivation research. Dörnyei, Zoltan, Ema Ushioda, eds. Motivation, Language Identity and the L2 Self. Clevendon, UK: Multilingual Matters, 43-65.

Martin, Marion, Gaynor Sadlo, Graham Stew (2006). The phenomenon of boredom. Qualitative Research in Psychology 3: 193-211.

Mikulas, William L., Stephen J. Vodanovich (1993). The essence of boredom. Psychological Record 43.1: 3-12.

Nett, Ulrike E., Thomas Götz, Lia M. Daniels (2010). What to do when feeling bored? Students' strategies for coping with boredom. Learning and Individual Differences 20.6: 626-638.

Pauli, Christine, Kurt Reusser (2006). Von international vergleichenden Video Survey zur videobasierten Unterrichtsforschung -entwicklung [From comparative international video surveys to video-based instructional research and development]. Zeitschrift für Pädagogik 52.6: 774-798.

Pekrun, Reinhard (2006). The control-value theory of achievement emotions: Assumptions, corollaries, and implications for educational research and practice. Educational Psychology Review 18.4: 315-341.

Pekrun, Reinhard, Krista R. Muis, Anne C. Frenzel, Thomas Götz (2018). Emotions at School. New York: Routledge.

Piechurska-Kuciel, Ewa (2008). Language Anxiety in Secondary Grammar School Student. Opole: Uniwersytet Opolski. 
Robinson, William Peter (1975). Boredom at school. British Journal of Educational Psychology 45: 141-152.

Ryan, Richard M. (2007). Motivation and emotion: A new look and approach for two reemerging fields. Motivation and Emotion 31.1: 1-3.

Seidel, Tina, Richard J. Shavelson (2007). Teaching Effectiveness Research in the Past Decade: The Role of Theory and Research Design in Disentangling MetaAnalysis Results. Review of Educational Research 77.4: 454-499.

Stephanou, Georgia, Georgios Gkavras, Maria Doulkeridou (2013). The role of teachers' self- and collective-efficacy beliefs on their job satisfaction and experienced emotions in school. Psychology 4. 3A: 268-278.

Taxer, Jamie L., Anne C. Frenzel (2015). Facets of teachers' emotional lives: A quantitative investigation of teachers' genuine, faked, and hidden emotions. Teaching and Teacher Education 49: 78-88.

Titz, Wolfram (2001). Emotionen von Studierenden in Lernsituationen-Explorative Analysen und Entwicklung von Selbstbericbtskalen [Emotions of students in learning situations, Exploratory analysis and development of Selbstberichtskalen]. Munster: Waxmann.

Tremblay, Paul F., Robert C. Gardner (1995). Expanding the motivation construct in language learning. The Modern Language Journal 79.4: 505-518.

Ushioda, Ema (2011). Language learning motivation, self and identity: Current theoretical perspectives. Computer Assisted Language Learning 24.3: 199-210.

Zawodniak, Joanna, Mariusz Kruk, Jonathan Chumas (2017). Towards conceptualizing boredom as an emotion in the EFL academic context. KSJ 5.4: 425-441.

\section{Author's address:}

Dino Dumančić

University of Zadar

Obala kralja Petra Krešimira IV. br. 2

23000 Zadar

E-mail: ddumancic@unizd.hr

Received: July 22, 2019.

Accepted for publication: September 25, 2019 